\title{
PELO REENCANTAMENTO DA PSICOLOGIA: EM BUSCA DA POSITIVIDADE EPISTEMOLÓGICA DA IMAGINAÇÃO E DA EMOÇÃO NO DESENVOLVIMENTO HUMANO
}

\author{
Bader Burihan Sawaia* \\ Daniele Nunes Henrique Silva **
}

\begin{abstract}
RESUMO: A entrada do homem na história é uma das questôes centrais das Ciências Humanas. $\mathrm{O}$ presente texto reflete sobre a contribuição de Angel Pino para evitar interpretaçóes reducionistas dessa questão, destacando a sua proposição de que essa passagem se dá pela imaginação, sendo ela inseparável da emoção, o que explica a singularidade e a criação humana apesar da determinação social. Para demonstrar essas ideias, Pino tornou-se um garimpeiro da obra de Vigotski, aprofundando três conceitos basilares: conversão, função e drama; que abarcam a totalidade e o movimento dialético da passagem da natureza para a sociedade e são fundamentais para compreensáo da produçáo imaginária, conforme ele defendia. Para ajudar nossa análise, recorremos às concepções de imagem, imaginação e emoção de Espinosa, seu filosofo predileto. Procuramos demonstrar que esses conceitos permitiram a Pino reencantar o processo de desenvolvimento do humano, recuperando o que lhe fora retirado: a estética e a liberdade.
\end{abstract}

Palavras-chave: Desenvolvimento humano. Drama; Imaginação. Emoção. Conversão função.

\footnotetext{
* Pontifícia Universidade Católica de São Paulo (PUC-SP), Faculdade de Ciências Humanas e da Saúde, São Paulo, SP., Brasil.

** Universidade de Brasília (UnB), Instituto de Psicologia, Brasília, DF., Brasil. E-mail de contato: daninunes74@gmail.com.
} 


\title{
For the re-enchantment of Psychology: in search of the epistemological positivity of imagination and emotion in buman development
}

\begin{abstract}
The entrance of man in History is one of the central issues of the Humanities. This paper reflects on Angel Pino's contribution to avoid reductionist interpretations of this matter, highlighting his proposition that this passage is made possible by imagination, a process inseparable from emotion, which explains the uniqueness of human creation despite social determination. To demonstrate these ideas, Pino became an explorer of Vygotsky's work, profoundly studying three basic concepts: conversion, function and drama, which cover the totality and the dialectical movement of the passage from nature to society and are the key to understand imaginary production, as he advocated. To help in our analysis, we bring to the discussion the concepts of image, imagination and emotion in Espinosa, Vygotsky's favorite philosopher. We argue that these concepts allowed Pino to reenchant the process of development of man, recovering what had been taken from him: aesthetics and freedom.
\end{abstract}

Keywords: Human development. Drama. Imagination. Emotion. Conversion and function.

\section{INTRODUÇÃO}

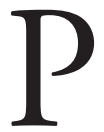

rofessor Angel Pino Sirgado foi um escavador da obra de Lev S. Vigotski, buscando, como ele próprio afirmou (PINO, 2000, p, 46): "[...] descobrir nos detalhes os sentidos de uma obra maior [...]". Dentre esses detalhes, escolheu aprofundar o que, segundo ele, representava a maior contribuiçấo de Vigotski à psicologia: a compreensão da interface entre cultura e desenvolvimento, sem cair no perigo, de um lado, "[...] da destituição do estatuto do sujeito sob um suposto determinismo do meio sócio-cultural [...]" e, de outro, no perigo da “[...] destituição da materialidade do psiquismo sob a ideia de mediação semiótica e a destituição da consciência pela ênfase nas emoçôes, defendendo a ideia de homem como totalidade que só se humaniza na história [...]" ${ }^{\prime}$. Nesse sentido, dar visibilidade a alguns desses detalhes analisados 
e aprofundados pelo Prof. Pino, ao longo de sua trajetória acadêmica, é uma tarefa empolgante e desafiadora, em razão da profundidade teórica com que ele tratava as questóes colocadas. Por isso, fizemos um enlace autoral ${ }^{2}$ para concretizar, nesse texto, o que Vigotski chama de enlace emocional: vinculação entre emoção e imaginação.

Como desbravador de novidades conceituais, ele não media esforços no tempo intelectual para lapidar os detalhes escolhidos. Seu conhecimento vasto lhe permitia atravessar campos teóricos variados, da Filosofia clássica e Teologia aos estudos modernos da Sociologia, Psicologia etc. Como pesquisador, aproximava-se da atitude ousada e criativa do artista, mas sempre preocupado com o rigor científico. A sua polêmica tese de livre docência, por exemplo, buscava demonstrar, por meio de uma meticulosa pesquisa microgenética, a passagem do biológico ao cultural, da natureza à história. Uma questão filosófica, o ponto zero, colocada teoricamente por Vygotsky e que Angel Pino se propôs a trabalhar cientificamente.

$\mathrm{Na}$ apresentação do livro: As marcas do humano: às origens da constituição cultural da criança na perspectiva de Lev S. Vigotski, decorrente de sua livre docência (PINO, 2005, p. 18), ele comenta:

Convencido da importância e da atualidade da temática presente na tese de Vigotski, eu pensei que seria extremamente oportuno tentar desvelar na realidade empírica da evolução da criança logo após o nascimento a maneira concreta como a natureza, constitutiva da sua condiçáo biológica, transforma-se sob a ação da cultura, fazendo da criança um ser bumano $[\ldots]$.

Aqui, tem-se uma contribuição fundamental à compreensão do desenvolvimento humano. Como filósofo humanista, aberto ao universal, ele nos lembrava sempre da concepção emancipadora e libertária (apesar de raramente usar essa palavra) do humano. E não é mera coincidência que nos últimos anos de sua vida Angel Pino tenha se dedicado, conforme veremos adiante, ao estudo da produção imaginária como condição fundante e explicativa da especificidade humana. 
Nessa linha seus textos (PINO, 1992; 2000; 2006, entre outros) auxiliaram os estudos na perspectiva histórico-cultural e sociocultural, no Brasil, a evitarem interpretaçóes reducionistas da complexa obra de Vigotski. Havia uma preocupação permanente de Monsieur Pino - como carinhosamente foi apelidado pelo Grupo de Pesquisa Pensamento e Linguagem (GPPL/Unicamp) -, em dimensionar o papel contraditório e dialético da relação entre desenvolvimento e cultura, distanciando tal abordagem teórica do materialismo mecanicista, mas sem abandonar os pressupostos marxistas. Esses posicionamentos levaram-no a pinçar aspectos pouco explorados (detalhes) na obra de Vigotski, mas fundamentais para se entender que a passagem da natureza para a história se dá pela imaginação, concepção que explica a singularidade e a criação apesar da determinação cultural.

\section{UMA PSICOLOGIA DA TOTALIDADE E DA DIALÉTICA E A BUSCA POR CONCEITOS MONISTAS}

Vigotski foi um dos primeiros psicólogos a apontar, em diferentes momentos de sua obra, as mazelas do separatismo epistemológico à psicologia dos anos 1920, instigando a substituição de conceitos clássicos que dividiam uma totalidade complexa por unidades de análise que apresentam, em "formas pequenas, as propriedades do todo". Como exemplo citava a mercadoria, "[...] a menor unidade de análise capaz de abarcar a totalidade do fenômeno psicossocial, como fez Marx, 'ao criar seu O Capital'”. (VIGOTSKI, 1927/1991, p. 393)

No tomo I, das Obras Escogidas, no texto: "La psique, la conciencia; el inconsciente" (1930/1991, p. 59), o psicólogo russo afirmava que um dos problemas mais difíceis da psicologia era aquele referente à cisão entre os processos psíquicos e fisiológicos:

La originalidad de la psicología dialéctica consiste justamente en que intenta determinar de un modo completamente nuevo su objeto de estudio, que no es otro que el proceso integral del comportamiento. Este se caracteriza por contar tanto con componentes psí- 
quicos como fisiológicos, aunque la psicología deba estudiarlos como un proceso único e integral [...].

Esse processo integral do comportamento revelava a concepção monista defendida por Vigotski. Para ele, a análise do fenômeno psíquico não podia ser realizada a partir de uma epistemologia dualista, mas dialética. Isso consiste em "[...] analizar un fenómeno en su totalidad como una configuración y sus partes como elementos orgánicos de la misma [...]". (VIGOTSKI, 1991, p. 60)

Vigotski combatia fortemente toda a tradição cartesiana que apregoava a cisão corpo e mente; razão versus emoção etc. (SAWAIA, 2000 ; 2014), bem como a separação entre psiquismo e sociedade. Por isso ele alegar a necessidade de uma psicologia capaz de trabalhar dialeticamente com duas categorias, aparentemente irredutíveis: subjetividade e objetividade.

Angel Pino continuou a tarefa de superar as dicotomias, evitando leituras reducionistas, aprimorando conceitos, desvelando questóes pouco exploradas e estimulando ousadias interpretativas para dar continuidade a sua missão de explicar a passagem do exterior ao interior, sem cair na causalidade simplificadora. Nessa sua empreitada, três destaques merecem nossa atenção, a saber: os conceitos de função, conversão e de drama. (PINO, 2000)

Para explicar a dimensão social do psiquismo, Vigotski desenvolveu o conceito que foi traduzido por internalizaçáo. Ele fez isso ao demonstrar que o desenvolvimento cultural envolve necessariamente três estágios: em si - para os outros - para si. Ele explica (VIGOTSKI, 2000, p. 24):

A personalidade torna-se para si aquilo que ela é em si, através daquilo que ela antes manifesta como seu em si para os outros. Este é o processo de constituição da personalidade. Daí está claro, porque necessariamente tudo o que é interno nas funçóes superiores ter sido externo: isto é, ter sido para os outros, aquilo que agora é para si. Isto é o centro de todo o problema do interno e do externo. 
Para Pino $(1995 ; 2000)$ esse conceito mal interpretado poderia dar margem a explicaçóes determinísticas e mecânicas; uma passagem direta do meio externo para o interno. Por isso, fez questão de advertir que no campo do materialismo histórico dialético, matriz referencial de Vigotski, não se devia abandonar o princípio dialético que promove a transformação daquilo que é social em algo que é para si. Para tanto, Pino esclarece e avança na proposição teórica apontada por Vigotski e afirma que aquilo que é internalizado das relaçôes sociais não se restringe à materialidade, mas ao sentido que elas têm para as pessoas.

Dizer que o que e internalizado e a significação dessas relaçóes equivale a dizer que o que e internalizado e a significaçẫo que o outro da relação tem para o eu; o que, no movimento dialético da relação, dá ao eu as coordenadas para saber quem é ele, que posição social ocupa e o que se espera dele. Dito de outra forma, é pelo outro que o eu se constitui em um ser social com a sua subjetividade. (PINO, 2000, p. 66)

Esse princípio norteador permite compreender que as relaçóes sociais se convertem em funçóes psicológicas superiores organizadas intrapsicologicamente. E, no decorrer dessas reflexóes, continuando em sua tarefa de evitar dualismo, Pino apresenta a instigante proposição de Vigotski sobre a condição dramática do psiquismo, contida no seu texto Manuscritos de 1929, traduzido e publicado com o título: Psicologia concreta do Homem. (VIGOTSKI, 1929/2000) ${ }^{3}$

Para explicar melhor essa ideia, Pino é primoroso. Parte da expressão Homo Duplex, cunhada por Vigotski nesse mesmo texto, para indicar que o homem é uma unidade, onde o outro permanece sempre presente como um não eu: um estranho essencial, e explica que a internalização envolve a conversão de dois em um - uma relação social para mim - em mim. Avança, defendendo a substituição do termo internalização/interiorização por conversão, para indicar com mais força que a determinação social não é um processo automático, ao contrário, pressupóe a atividade do sujeito. 
É importante ressaltar que Angel Pino, na década de 1990, já problematizava a concepção mecanicista do conceito de internalização. Em um trabalho de 1992 (PINO, 1992), em busca da precisão, ele propóe a substituição da dupla conceitual exterior e interior por público e privado. Para Pino, o caráter privado do sentido e o caráter público do significado não eram dicotômicos, mas constituíam dialeticamente uma unidade de contrários na intersubjetividade. Essas primeiras análises permitiram a defesa, posterior, do conceito de conversão e com ele a ideia de que não refletimos o real de forma automática, mas o experimentamos de forma singular: "A entrada na cultura é o momento de distanciamento do homem da realidade em si, a qual se desdobra nele na forma de imagem". (PINO, 1992, p. 65)

Esse conceito, de conversão, por sua vez, abre a possibilidade para se compreender melhor a subjetividade na forma de drama, compondo um conjunto conceitual que traz implicaçóes importantes para os estudos no campo da Psicologia, pois, de um lado, não nega a determinação social, mas a atravessa pela criação e, de outro, elimina a visão clássica de psiquismo estruturado e harmonioso. "A vida é uma luta interna de posiçóes sociais convertidas em uma dinâmica de personalidade que, portanto, não pode ser harmônica, mas tensionada, dramática, no sentido de sistemas contraditórios [...]". (VIGOTSKI, 2000, p. 35)

Vejamos essa análise a partir do sonho de Kaffir:

O drama realmente está repleto de ligaçôes de tal tipo: o papel da paixão, da avareza, dos ciúmes, em uma dada estrutura da personalidade. Um caráter divide-se em dois em Macbeth - Freud. O drama realmente está repleto de luta interna impossível nos sistemas orgânicos: a dinâmica da personalidade é o drama. (VIGOTSKI, 2000, p. 34)

Tais tensões, que vão sendo consolidadas subjetivamente de forma dramática, são visivelmente observadas nas escolhas que cada um de nós pode efetuar na vida. É o que ocorre na tragédia de Shakespeare: Othelo ama Desdemona. Desdemona revela a reciprocidade desse amor. Contudo, Iago faz o mouro crer que Desdemona o trai com Carlos. 
Othelo, então, convicto da traição decide matar a esposa. No ato $\mathrm{V}$, cena II (SHAKESPEARE, 1947/2002) o protagonista declara seu conflito (diante da esposa dormindo):

OTELO - Esta é a causa, minha alma. Oh! Esta é a causa! Não vo-la nomearei, castas estrelas! Esta é a causa! Não quero verter sangue, nem ferir-lhe a epiderme ainda mais branca do que neve e mais lisa que o alabastro. Mas é fatal que morra; do contrário, virá ainda a enganar mais outros homens. (p. 165).

Na tragédia, como na vida, a dinâmica dramática da personalidade implica um conjunto de relações sociais que são encarnadas contraditoriamente em um determinado indivíduo (numa totalidade), resultando em uma luta interna; um choque do sistema das funçóes psicológica superiores. Vigotski (2000, p. 27) afirma:

[...] se atrás das funçôes psicológicas estão geneticamente as relaçôes das pessoas, então: 1) é ridículo procurar centros especiais para as funçóes psicológicas superiores ou funçôes supremas no córtex (partes frontais - Pavlov); 2) deve explica-las não com ligaçóes internas orgânicas (regulação), mas de fora - daquilo a que a pessoa dirige a atividade do cérebro de fora, através de estímulos; 3) elas não são estruturas naturais, mas construçóes; 4) o principio básico do trabalho das funções psíquicas superiores (da personalidade) é social do tipo interação das funçôes, que tomou o lugar da interação das pessoas. Mais plenamente elas podem ser desenvolvidas na forma de drama.

A noção de psiquismo como drama (choque de sistemas) e de dinâmica dramática da personalidade também é importante para rebater a falsa crítica de que a concepção Vigotskiana de desenvolvimento é evolucionista. Afinal, como é possível que haja harmonia no psiquismo se o contexto é de luta de classes?, provoca Vigotski (2000, p. 35). 
Mas há um outro conceito que merece destaque nesses desdobramentos e que estão coadunados ao nosso argumento sobre a contribuição de Pino a favor da visão monista do psiquismo de Vigotski; o choque das funções implica necessariamente na equivalência das próprias funçôes. Nesses termos, é possível explicar emoção, imaginação e razão sem hierarquia, refutando a negatividade a que as primeiras eram submetidas pela Psicologia tradicional. Função, então, “[...] implica em conceber o psiquismo como algo dinâmico, que está sempre refazendo em movimento [...]. O fato de usar esse conceito demonstra que Vigotski entendia as funções mentais como um acontecer permanente [...]". (PINO, 2000, p.70)

De fato, a inadequação está no rompimento dos nexos entre as funçôes, como fazia a psicologia clássica, hierarquizando-as de forma que uma se tornasse senhora das demais, como ocorreu com a consciência, bloqueando o movimento, o desejo, o corpo, ou anulando a força da atividade humana.

\section{A POSITIVIDADE DA IMAGINAÇÃO E DA EMOÇÃO: O PROBLEMA DA LIBERDADE}

As reflexôes anteriores e os conceitos de mediação (conversão, função e dinâmica dramática do psiquismo) ampliam a compreensão da presença constitutiva da imaginação e dos afetos no processo de desenvolvimento. E mais, permitem a compreensão da unidade entre emoção e imaginaçáo no processo de desenvolvimento.

Continuando sua travessia na obra de Vigotski, em busca da compreensão da "passagem das forças sociais para forças individuais da atividade psíquica”, Angel Pino, a partir de 2002 (PINO, 2006), aprofunda seus estudos na interface entre significação, produção imaginária e atividade estética. Ele explora as relações entre a produção de imagem, o processo de significação dessas imagens, a reelaboração plástica das imagens simbolizadas (no plano da imaginação) e a produção estética (resultado da produção imaginária). 
Segundo ele é no plano da imaginaçáo que começa o processo de criação humana; antes da materialização, a criação ocorre no Imaginário, e não se limita a exclusividade do campo artístico mas implica todas esferas da vida que se referem à resolução de problemas:

Se a função imaginária opera no campo que interliga o real e o simbólico e se o papel da imagem mental e de operar a conversáo dos sinais naturais em significaçôes culturais, então a produção imaginária adquire existência real quando deixa o campo do imaginário e se constitui como produção simbólica, qualquer que ela seja. (PINO, 2006, p. 74)

Aqui encontram-se as contribuiçóes que queremos ressaltar acerca da leitura de Pino da obra de Vigotski: a positividade da imaginação e da emoção - dimensôes psíquicas que carregaram na história das ideias o estigma da (des)razão. De fato, a emoção como perturbatio animii (SAWAIA, 2001) e a imaginação como extensão do funcionamento mnemônico, ficaram ambas restritas ao campo da arte ou da loucura. Desse modo os esforços em compreender o funcionamento imaginativo e as emoçóes, na maioria das vezes, apresentaram-se de forma difusa e não complementar nas distintas análises teóricas. (SILVA; CASTRO; BARBATO, 2010)

A divergência radical com a psicologia do século XIX, que denominará de velha ou tradicional, leva Vigotski (1987; 1991) a buscar na filosofia monista de Espinosa orientaçóes para superar a visão das emoções e imaginação como opostas à razão e com funcionamento separado do pensamento. Espinosa também oferece um estatuto diferente à imaginação (SAWAIA, 2009) a partir de sua ideia de imagem como primeiro nível do conhecimento e, portanto, constitutiva dele e também do trabalho humano. Nesses termos, a história resulta da capacidade imaginativa de apresentar ao real algo inaugural, que altera a paisagem do mundo, a consciência perde lugar de senhora da razáo e do conhecimento e inverte-se a concepção de que imaginação e emoção são da ordem do erro. A mente só erra porque imagina o que sente, mas não erra por imaginar o que sente ${ }^{4}$ 
As reflexôes sobre imaginação de Vigotski e de Pino são iluminadas quando se lembra a influência de Espinosa na obra de Vigotski no que tange a ideia de imagem. As imagens não são meramente reflexos daquilo que se vê; um espelho, também não são fictícias, mas signos representativos da fisicidade 5 .

Imagem na obra de Espinosa: é o primeiro nível de conhecimento, a forma como experimentamos o mundo. É por meio de imagens das afetaçóes do corpo que a mente conhece o mundo. Considerando que essas imagens não são cópias dos objetos que nos afetam, não conhecemos o mundo tal qual se apresenta fisicamente, mas pela imagem que ele nos provoca. É por conhecer o mundo por imagens que podemos sentir com e pelo outro, criar conceitos abstratos e projetar o diferente. Portanto, "[...] além da ilusão, a imaginação apresenta um poder original de intervenção e de ligação das representações [...]". (RISK, 2006, p. 138)

Pino (2006) completando tal reflexão, vai destacar a base sócio-histórica da imaginação, afirmando que a criação é a própria expressão da vida cotidiana e se articula de forma interdependente com as condiçóes materiais de existência humana. Por isso, criar não é algo acidental mas demarcado historicamente. Toda a atividade criadora parte da experiência, ou melhor, da forma como se percebe internamente e externamente o mundo, a partir dos processos de significação. A imaginação, então, se configura como meio de ampliar a nossa experiência, pois podemos experimentar o que não vivemos diretamente, possibilitando-nos assimilar contextos históricos, sociais e individuais alheios (SILVA, 2012) ou por meio da arte.

Todas as nossas vivências fantásticas e irreais transcorrem, no fundo, numa base emocional absolutamente real. Deste modo vemos que o sentimento e a fantasia não são dois processos separados entre si mas, essencialmente, o mesmo processo, e "[...] estamos autorizados a considerar fantasia como expressão central da reação emocional". (VYGOTSKI, 1999, p. 264)

Mas o contrário também é verdadeiro; a fantasia influencia os sentimentos, pois toda representaçáo criadora encerra em si elementos afetivos. Ao ler uma história, imaginar algo, imediatamente experimen- 
tamos sentimentos que emergem da nossa imaginação. No caso das crianças pequenas, por exemplo, quando imaginam que há um fantasma debaixo da cama, vivem o sentimento de medo e pavor com tanta realidade que, muito comumente, náo se mexem na cama até dormirem profundamente. Quando assistimos a uma peça teatral, outro exemplo, e somos impactados pelo enredo apresentado, choramos e/ou rimos com o herói representado, nos transmutamos para o personagem, nos identificamos com ele, sentimos o que ele está sentindo. Essa experiência decorre de nossas possibilidades imaginativas de se deslocar sensivelmente na direção do outro sem se confundir com ele. (BAKHTIN, 2003)

Vigotski aprofunda essa complexidade em diferentes textos, dando importantes indícios dessa trama conceitual, quando tenta compreender as emoçóes humanas. A ideia de que o homem é afetado pela imaginação retira a emoção da condição de mero reflexo das forças externas e da massificação e a liberta da fisicidade. A imaginação permite que os homens que vivem na mesma condição social sejam afetados de diferentes maneiras por uma mesma coisa.

É no conceito de perejivánie (traduzido por experiência emocional) que Vigotski apresenta, de forma mais explícita, a relação entre imaginação e emoção no processo de conversão do exterior ao interior, da relação entre a criança e o ambiente, para indicar que não reagimos imediatamente à sociedade, mas à experiência vivida que, como ele destaca, é emocional. (VINHA; WELCMAN, 2010) Ele apresenta esse conceito em palestra para mães, realizada nos últimos anos de sua vida, com o objetivo de explicar a singularidade de cada filho, apesar das semelhanças ambientais. $\mathrm{O}$ conceito pretende elucidar que a criança não reage imediatamente e uniformemente à sociedade, mas a experimenta emocionalmente e que esta não se separa da interpretação cognitiva.

Em outra obra, Vigotski (1987) vai chamar de enlace emocional a vinculação entre emoção e imaginação, sugerindo que todo o sentimento é pensado em imagens que formam um determinado estado de ânimo. Em outras palavras, as imagens da fantasia transformam-se em linguagem interior dos sentimentos, pois ao experimentar determinadas sensaçóes, imediatamente, o homem pensa em imagens. (SILVA; ABREU; COSTA, 2015) 
"A imaginação cumpre um papel de libertar o homem da sua condição de vida, das leis da natureza na medida que possibilita a reconstrução da realidade e o domínio da sua própria evoluçãa”. (PINO, 2006) Assim sendo, a possibilidade de atuar com liberdade surge na consciência dos homens em função da imaginação. Isso quer dizer que "os homens só podem atingir um grau de liberdade se forem criativos". (SAWAIA, 2009, p. XX) A emoção é o radar ético das formas de afetação do meu corpo e mente pelos encontros que a existência me oferece. Pino (2006, p. 49) aprofunda essas análises sobre a imaginação na ontogênese. Ele afirma:

[...] as produçóes imaginárias constituem um pré-requisito de toda produção humana, material e simbólica. Isto equivale a dizer que a atividade imaginária precede toda e qualquer outra forma de atividade humana de natureza criativa; o que permite afirmar que, em última instância, o imaginário é o que define a condição humana do homem.

\section{DESENVOLVIMENTO COMO LIBERDADE}

Iniciamos esse item resumindo as reflexóes anteriores nessa última frase de Pino: "[...] o imaginário (unidade emoção e imagem) é o que define a condição humana do homem [...]" e destacando que esta condição é a de liberdade. Ele não transige deste pressuposto em nenhum de seus textos, rebatendo a interpretação de que a concepção Vigotskiana de desenvolvimento é evolucionista. Ao contrário, ele implica liberdade, mas não como a realização de uma essência humana. É liberdade que resulta da capacidade criativa do homem. Assim, Pino destaca que o desenvolvimento não é natural, mas histórico, e nos defronta com um aparente paradoxo: o desenvolvimento tem como fonte o ambiente e a criação, a determinação e a liberdade. Paradoxo que suas reflexốes apresentadas anteriormente sobre imaginação e emoção ajudam a esclarecer que o desenvolvimento humano está atrelado à atividade e, portanto, tem o senso de apropriação-transformação. (BROSSARD, 2010, p. 100)

O conceito de desenvolvimento em Vigotski (2001) tem a ideia de ruptura com o desenvolvimento natural, com as leis impositivas, 
da natureza e dos czares: "A espécie humana não vai deixar de rastejar diante [...] dos reis e do capital, para inclinar-se docilmente diante das leis obscuras da hereditariedade e da seleção sexual cega!" (VIGOTSKI, 2001, p. 463)

Desenvolvimento remete ao futuro construído na luta pela libertação das forças opressivas (biológicas e sociais), como resultado da busca de não permanecer como algo tornado, mas que está no movimento absoluto do vir a ser. Ou seja, o desenvolvimento é atividade revolucionária (não adaptadora), fruto da capacidade humana de alterar a totalidade histórica, mesmo sendo por ela configurado.

A imaginação (inseparável da emoção) aparece como processo psicológico fundamental para que o desenvolvimento adquira seu caráter de atividade revolucionária. Nela está a possibilidade humana de alterar a história. Perspectiva fundamental para "[...] evitar a reificação da imaginaçáo como um construto psicológico que permite que o velho argumento filosófico-teológico da causa primeira retorne ao jogo [...]". (NEWMAN; HOLZMAN, 2002, p. 64) Nessa mesma direção, Angel Pino, em diferentes momentos de sua obra, em suas palestras e aulas defendia uma ontologia revolucionária guiada pelas produçóes imaginárias. Essa defesa abarcava preocupações conceituais e teóricas complexas, que foram demonstradas aqui, mas também podiam ser encontradas em sua posição política e comprometida com a educaçáo das crianças.

Em um encontro com professores da Secretaria Municipal do Rio de Janeiro, entre 2004-2006, com um auditório de mais de 500 lugares lotado, Monsieur Pino se emociona ao falar sobre o papel revolucionário da imaginação na ontogênese. Nessa palestra, ele adverte aos professores sobre a necessidade de a escola incentivar a capacidade humana criativa e, também, transgressora das crianças. A audiência escutava atenta aos ensinamentos do mestre; a escola deveria ser o lócus da produção imaginária, ao invés de cerceadora.

No prefácio de um livro (SILVA, 2012), preocupado com as questóes da escola e da formação estética das crianças e professores, ele alertava para o desafio de descobrir a importância da imaginação na constituição criadora da criança. Ele defendeu, assim como Vigotski, a centralidade que a escola tem "[...] na formação (educação) da nature- 
za humana da Criança". "Assim, a educação se desdobra como o mais amplo problema do mundo: o problema da vida como criação [...]". (VIGOTSKI, 2001, p. 460)

$\mathrm{Na}$ teoria de ambos, liberdade humana da criança não é um princípio abstrato de liberdade ou livre arbítrio, não é também a afirmação do indivíduo contra constrangimentos sociais. Liberdade e determinação não são excludentes, ao contrário não há o humano fora da história. O homem como totalidade só se humaniza na história. Para que essa relação dialética não se cristalize em causalidade mecânica, a vida deve ser uma criaçấo constante, um ritual estético que surge não da tendência para a satisfação de pequenas necessidades contingenciais, mas do desejo de liberdade.

Paramos o texto por aqui, completando um círculo dialético que se iniciou na visão de Angel Pino da entrada do homem na cultura e de seu desenvolvimento como homem humano, e volta ao ponto de partida, transformando-o em questão de liberdade. Esse processo mostra a potência reflexiva desse pensador e a sua contribuição fundamental para evitar desvios nas interpretaçóes das ideias Vigotskianas. Ele marca a história da psicologia histórico-cultural e sócio-histórica como um revolucionário epistemológico, mas também como mestre revolucionário.

Como mestre, lembramos, Pino foi um farol de ideias, iluminador, provocativo, um criador de ZDP. Suas supervisóes podiam durar tardes intermináveis e avançar na noite, que não poupava aos alunos, orientandos e parceiros de ideias com sábias críticas, orientaçóes precisas e apoio público. Como filosofo humanista não se cansava de alertar seus alunos, colegas e público em geral sobre os desafios éticos e políticos/ ideológicos que a contemporaneidade apresentava e como eles apareciam nos conceitos psicológicos. Era assim que ele procurava nos erguer à sua gigantesca altura. Era assim que nos preparava para o que estava adiante, sendo um pensador para além de seu tempo ${ }^{6}$.

\section{REFERÊNCIAS}

BAKHTIN, M. Estética da criação verbal. 4a. ed. São Paulo: Martins Fontes, 2004. 
BROSSARD, M. Le Développement comme transformation par appropriation des oeuvres de la culture. In: CLOT, Y. Vygotski Maintenant. Paris: La Dispute, 2010 .

CHAUI, M. Espinosa: poder e liberdade. In: BORON, A. A. (Org.). Filosofia politica moderna. De Hobbes a Marx. São Paulo; CLACSO, DCP-FFLCH/USP. 2006. Disponível em: http://bibliotecavirtual.clacso.org.ar/ar/libros/secret/ filopolmpt/filopolmpt.htm. Acesso em 30 de maio de 2015.

2001.

. Desejo, Paixão e Ação na Ética de Espinosa. São Paulo: Cia das Letras,

ESPINOSA, B. Ética. Belo Horizonte: Autêntica, 2008.

LORDELO, L. da R. A crise na Psicologia: análise da contribuição histórica e epistemológica de L. S. Vigotski. Psic.: Teor. e Pesq., Brasília, v. 27, n. 4, p. 537-544, dez. 2011. Disponível em: http://dx.doi.org/10.1590/S0102$\underline{37722011000400019}$. Acesso em 30 maio de 2015.

NEWMAN, F.; HOLZMAN, L. Lev Vygotsky - cientista revolucionário. São Paulo: Edições Loyola, 2002.

PINO, A. A produção imaginária e a formação do sentido estético. Reflexôes úteis para uma educação humana. Pro-posiçôes, v. 17, n. 2(50), maio/ago., 2006.

. As marcas do humano: às origens da constituição cultural da criança na perspectiva de Lev S. Vigotski. São Paulo: Cortez. 2005.

. O social e o cultural na obra de Vigotski. Educ. Soc., v. 21, n. 71, p. 45-78, jul. 2000. Disponível em http://dx.doi.org/10.1590/S010173302000000200003. Acesso em 30 de maio de 2015.

. As categorias de público e privado na análise do processo de internalização. Educ. Soc., n. 42, p. 315-327, 1992.

RISK, H. Compreender Spinoza. Editora Vozes: Petrópolis, 2006.

SAWAIA, B. B. Psicologia e desigualdade social: uma reflexão sobre liberdade e transformação social. Psicologia \& Sociedade, v. 21, n. 3, p. 364-372, 2009. Disponível em: http://www.scielo.br/pdf/psoc/v21n3/a10v21n3.pdf. Acesso em 30 de julho de 2014.

SAWAIA, B. B. A emoção como locus da produção do conhecimento. In: CONFERÊNCIA DE PESQUISA SÓCIO-CULTURAL, 3., 2000. Campinas. Anais... Campinas: Unicamp/FE, 2000. Disponível em: https://www. fe.unicamp.br/br2000/credi.htm. Acesso em 30 de maio de 2015. 
- As artimanhas da Exclusão - análise psicossocial e ética da desigualdade social. 14. ed. Niterói: Vozes, 2014.

SHAKESPEARE, W. Otelo: o mouro de Veneza. Disponível em: http://www. ebooksbrasil.org/adobeebook/otelo.pdf. Acesso em 30 de maio de 2015. [Versão para digital por eBooksBrasil.com, julho de 2000].

SILVA, D. N. H.; COSTA, M. T. M. S.; ABREU, F. S. D. de. Imaginação no faz de conta: o corpo que brinca. In: SILVA, D. N. H.; ABREU, F. S. D. de. (Orgs.). Vamos brincar de quê? Cuidado e educação no desenvolvimento infantil. São Paulo: Summus, 2015, p. 111-131.

SILVA, D. N. H.; CASTRO, J.; BARBATO, S. B. La imaginación creadora: aspectos histórico-genealógicos para La reconsideración de una psicología de la actividad y la mediación estética. Estudios de Psicología, v. 31, p. 253-277, 2010.

SILVA, D. N. H. Imaginação, criança e escola. São Paulo: Summus, 2002.

SILVA, P. J. C. da. A subversão das paixóes na primeira modernidade: entre psicopatologia e sabedoria. Revista Latinoamericana de Psicopatologia Fundamental, v. 12, n. 1, p. 209-217. Disponível em http://ref.scielo.org/v5dcvv. Acesso em 22 de julho de 2014.

VYGOTSKI, L. S. Teoría de las emociones: Estudio histórico-psicológico. Madrid: Akal, 2004. . Psicologia Pedagógica. São Paulo: Martins Fontes, 2001. . Manuscrito de 1929. Educ. Soc., v. 21, n. 71, p. 21-44, 2000. . Psicologia da Arte. São Paulo: Martins Fontes, 1999. . La genialidade y otros textos inéditos. Buenos Aires: Editorial Almagesto, 1998. [Compilado por BLANK, G.]. . Obras escogidas. Madrid: Visor, 1991.

VINHA, M. P.; WELCMAN, M. Quarta aula: a questão do meio na pedologia, Lev Semionovich Vigotski. Psicol. USP, São Paulo, v 21, n. 4, p. 681-701, 2010. Disponível em http://ref.scielo.org/93gc5d. Acesso em 03 de junho de 2015.

WORTMEYER, D. S.; SILVA, D. N. H.; BRANCO, A. U. Explorando o território dos afetos a partir de Lev Semenovich Vigotski. Psicol. estud., Maringá, v. 19, n. 2, p. 285-296, jun. 2014. Disponível em http://ref.scielo.org/ftrw7y. Acesso em 30 de maio de 2015. 


\section{NOTAS}

1. Frase proferida pelo Prof. Angel Pino durante a III Conferência de Pesquisa Sociocultural, em 2000, como debatedor do simpósio intitulado: Las emociones y la personalidad: desafios para su reconstrucción desde una perspectiva histórico-cultural - ISCAR, 2000 Brasil.

2. Este artigo é a síntese de uma parceria insinuada por Angel Pino, em 2003. Numa tarde prolongada de orientação, ele indicou à sua orientanda (autora deste artigo) a leitura de uma tese intitulada: $O$ sentido do Sentido em Vygotsky: uma aproximaçâo com a estética e a ontologia do ser social de Lukács. Pino fora membro da banca de defesa da tese e estava muito empolgado com o que acabara de ler. O material tinha sido defendido por Maria Regina Namura e orientado pela Profa. Bader Sawaia (também autora deste texto). Pino, então, sugere à sua jovem orientanda que se aproxime das pesquisas produzidas por tal orientadora. Em 2015, seguindo seus conselhos, as duas autoras se encontram para a realização deste artigo e o desenvolvimento de novas investigaçóes. A coautoria, portanto, deste texto é fruto da preocupação epistemológica de Pino em promover junçôes analíticas e entre pessoas para superar os dualismos clássicos da psicologia.

3. Assim alerta para uma ideia vigotskiana pouco debatida a época, e hoje alvo de grande interesse: o psiquismo como drama.

4. O conceito de imagem espinosista ilumina o conceito central de Vigotski: significação, pois garante a ideia de que a afetação que nosso corpo e mente sofrem nos encontros não é cópia do objeto que nos afeta, podendo assim ser tanto função da ilusão quanto da criação, qualidades que dependem das condições de existência e dos encontros. Lembrando, assim, que a imaginação é prioritariamente a capacidade de o homem criar, mas uma capacidade que tem base sócio-histórica.

5. Segundo Chaui (2011), Espinosa, como os filósofos do século XVII, emprega a palavra imaginar no sentido de perceber e de percepção, o que significa que imaginar não é inventar pela fantasia, mas perceber sensorialmente as coisas. Imaginar é uma força do corpo que cria imagens de si a partir do modo como é afetado pelos demais corpos.

6. O suporte que Pino deu ao NEXIn (Núcleo de Estudos da Afetividade no Processo de Exclusão/Inclusão Social - PUC/SP), do qual participamos, é emblemático de sua postura de mestre. Nunca comentamos isso com ele, mas ele deu, no final do século $\mathrm{XX}$, o que podemos chamar de apoio público à defesa da centralidade e positividade da emoçáo, desempenhando papel fundamental para que superássemos a insegurança inicial de trilhar caminhos não dominantes entre os leitores de Vigotski, que era o das emoçóes e o da influência de Espinosa, filosofo preferido de Vigotski.

Recebido em 15 de junho de 2015.

Aprovado em 30 de julho de 2015.

DOI: http://dx.doi.org/10.1590/CC0101-32622015V35ESPECIAL154115 